\title{
Epítetos y expresiones de apariencia épica en las comedias de Aristófanes*
}

\author{
Luis M. Macía Aparicio \\ Universidad Autónoma de Madrid \\ luism.macia@uam.es \\ Epithets and phrases of epic appearance in Aristophanes' comedies
}

\begin{abstract}
Al leer las comedias de Aristófanes, nos encontramos con numerosos epítetos que por su formación y significado se parecen a los que caracterizan al lenguaje de la épica. A nuestro entender, ese hecho demuestra la vigencia de la épica en tiempos de Aristófanes y la facilidad del público para captar las alusiones a ese género, lo que da pie al cómico para provocar la risa a su costa. Al analizar esos aparentes epicismos, encontramos algunos que, en efecto, son tradicionales, están ya en la épica y, ocasionalmente, en la lírica o en el drama anteriores o contemporáneos de Aristófanes, otros, catalogables como epicismos aristofánicos, que solo están en la épica tardía o carecen total o parcialmente de representación fuera del cómico y algunos, en fin, que no son más que aparentes epicismos, pues no están en la épica, sino en la lírica, particularmente en la poesía hímnica.
\end{abstract}

Palabras clave: Aristófanes; parodia épica; epítetos épicos.
When reading Aristophanes' comedies, we find many epithets that, because of their formation and meaning, bear resemblance to those that are characteristic of the epic language. In our opinion, this fact proves the relevance of epic in the time of Aristophanes and the ease of the public being able to grasp the allusions made to that genre, which allows the playwright to bring about their laughter at its expense. When analyzing these apparent epicisms, we find that some of them are indeed traditional and are used in the epic poetry and, occasionally, in the lyric and dramatic poetry previous to or contemporaneous with Aristophanes; others can be labelled as Aristophanic epicisms because they are only found in late epic or are totally or partially absent in other writers; finally, some of them are only apparent epicisms, since they are not used in epic but in lyric, especially in hymnic poetry.

Key words: Aristophanes; epithets; apparent epicisms.

* Este trabajo se sitúa en la línea hace tiempo emprendida del estudio de la presencia de Homero en Aristófanes (Macía 1998, 2000. A ellos remitimos para cuestiones de metodología). En la referencia a autores y obras seguimos las del $D G E$ (vol. III, pp. XXIII-CIV), pero nos servimos de las ediciones contenidas en la base de datos $T L G$ (versión 8.0, 1999) que incluye autores que no contenía la versión que pudimos manejar en aquellos trabajos. 
Es frecuente, sobre todo en pasajes que incluyen himnos ${ }^{1} \mathrm{o}$ invocaciones a los dioses, la aparición de algunos términos, particularmente epítetos, que nos recuerdan los que encontramos en la épica arcaica, en Homero sobre todo, en la lírica de esa misma época o en ambos géneros. La intención de dicho empleo es casi siempre paródica y está al servicio de la comicidad, como señalaremos al estudiar los ejemplos que aportamos.

Asumimos que la identificación de los términos apelando al recuerdo tiene un componente de subjetividad que puede llevar a excluir términos —no me refiero a algunos, como $\beta \alpha \sigma i \lambda \varepsilon v ́ s$ y otros del estilo, de empleo demasiado común fuera de la poesía, que deberían entrar- pero también permite encontrar otros que tienen efectivamente cabida en la poesía anterior a Aristófanes y otros que, o bien son de empleo exclusivo en este poeta, o bien, y son uno de los puntos que consideramos más interesantes de este trabajo, no aparecían en la poesía anterior pero se vuelven a emplear en la épica postclásica, como si Aristófanes fuera un creador de epicismos.

Razones subjetivas también, unidas a la conveniencia de ajustarse a las dimensiones de un artículo de revista, nos mueven a seleccionar algunos ejemplos del conjunto. Semejante restricción se apoya además en el hecho de que los ejemplos encontrados se pueden distribuir en tres grupos, en los que podremos comprobar hasta qué punto es Aristófanes deudor de la poesía anterior en el uso de esos términos o independiente de ella y creador de términos que consideramos épicos por su presencia en la épica postclásica.

\section{Epitetos tradicionales}

Analizaremos en este grupo los adjetivos que tienen presencia ya en los poemas homéricos y de otros épicos antiguos y también - aunque el hecho es poco frecuente - en los poetas de los siglos VIII-V a. C. y que muchas veces tienen continuidad en la épica postclásica. Los llamamos tradicionales porque estamos convencidos de que la división entre la épica y la lírica arcaicas es

${ }^{1}$ Respecto a la adscripción de la poesía hímnica al género épico o al lírico, véase lo dicho en la n. 5 de Macía 2000. Añádase que no todos los pasajes hímnicos de las once comedias presentan epítetos de apariencia épica. En el largo pasaje de Ranas (vv. 342-460) que contiene himnos a distintos dioses apenas encontramos tres o cuatro epítetos dignos de mención y,

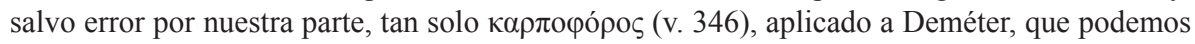
encontrar en Píndaro (P. 4.6; N. 6.9) y Eurípides (IT 1235; Io. 475), tiene representación en la épica, aunque, eso sí, en Juan de Gaza, un poeta del siglo VI d. C. 
mucho menos tajante de lo que las denominaciones sugieren, ya que, sobre todo en el léxico, presentan con frecuencia rasgos comunes ${ }^{2}$.

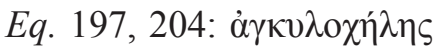

Forma parte de un pasaje en el que se parodia un oráculo por medio de unos versos cuyo parecido con algunos de Homero es notable ${ }^{3}$. El epíteto que estudiamos aparece solamente en tres versos de Homero: Il. XVIII $428=$ Od. XXII 302 (integrado en el pseudohesiódico Escudo, v. 405) e Il. XIX 538, referido a los buitres y, como en Aristófanes, al águila; la épica tardía no utiliza el epíteto ni tampoco lo hace ningún autor entre los siglos VIII-V. Aristófanes es, pues, el único conservador de un homerismo en el elenco de autores y géneros literarios que consideramos.

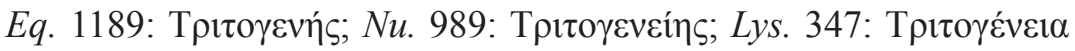

Epíteto de Atenea $^{4}$, se presenta en Aristófanes en tres contextos métricos distintos: tetrámetros anapésticos catalécticos en Caballeros, trímetros yámbicos en Nubes y parte de un himno, como ya hemos dicho, en Lisistrata. Su estructura prosódica es apta para la poesía dactílica, que, en esta ocasión, ofrece numerosos ejemplos del adjetivo.

2 Sobre ello ha insistido recientemente Platter 2007. Nuestro punto de mira inicial es la épica, pese a la comunidad con la lírica que acabamos de mencionar y pese a que en algún caso la parodia aristofánica afecta a poetas líricos (véase un completo repertorio de ejemplos en Kugelmeier 1996). Continuamos así en la línea que hemos seguido en nuestros trabajos anteriores; además pensamos que el estudio de la presencia de Aristófanes en la lírica o en el teatro, que es el género que evidentemente más le interesa parodiar a Aristófanes, requeriría sendos estudios particulares.

${ }^{3}$ Para el análisis del pasaje en su conjunto, véase Valk 1964, p. 297. Del parecido con pasajes homéricos y de otros autores en que se incluyen referencias a animales como parte de oráculos se hace eco Gil 1995, quien, sin embargo, ni en este ni en ninguno de los pasajes que analizamos pertenecientes a esas dos comedias alude al posible carácter épico de los epítetos.

${ }^{4}$ Respecto a los problemas que plantea la cantidad larga de la /i/ y acerca de la posible significación del epíteto, véase García Blanco y Macía 1998, ad IV 515, y la nota al pasaje de Heródoto que citamos más adelante en Schrader 1985. En cuanto al comentario de López Eire 1994, excelente por lo demás, tan solo enumera los ejemplos aristofánicos del epíteto, sin entrar - tampoco en el epíteto del v. 773 comentado más abajo- en su posible dependencia homérica. 
Homero lo emplea cuatro veces; en dos de ellas (Il. IV 515; Od. III 378),

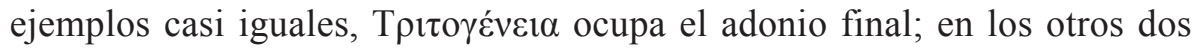
(Il. VIII 39 = XXII 183) va en interior de verso. En Hesíodo son dos los ejemplos, Th. 895 y en el pseudohesiódico Escudo, v. 197, muy parecido, por cierto, al ejemplo de la Odisea recién mencionado. En ambos el epíteto ocupa el adonio final. En último término, aparece en h.Min. 4, en acusativo a comienzo de verso.

La tendencia a que el epíteto constituya el adonio final del hexámetro, apreciable ya en la épica antigua, se confirma en la épica tardía, siempre

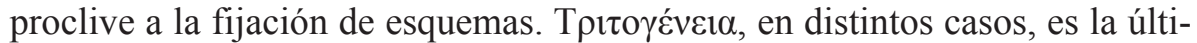
ma palabra en los diez ejemplos en que la usa $\mathrm{Nonno}^{5}$, en ocho de los once en que aparece en los Posthomérica de Quinto de Esmirna ${ }^{6}$ y en sus dos apariciones en las Argonáuticas Órficas (vv. 66 y 492).

Entre los siglos VIII y V a. C., descontados los tres ejemplos de Aristó-

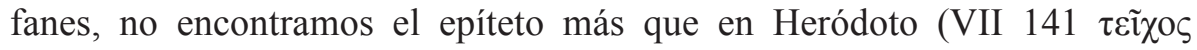

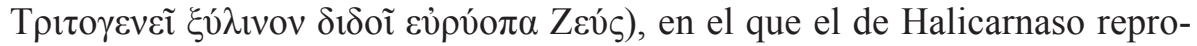
duce una respuesta de la Pitia a los atenienses, transcrita en los hexámetros dactílicos propios de ese tipo de mensajes.

Como resultado de nuestra búsqueda, parece aceptable afirmar que estamos ante un epíteto claramente épico y que entre Homero y Aristófanes es solamente el cómico el que se hace eco de él, pues no creemos que pueda añadirse a la nómina de los que lo conservan a Heródoto, quien, a diferencia del cómico, que usa voluntariamente el epíteto, lo transmite literalmente en su narración como palabras ajenas.

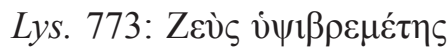

Con estas palabras concluye un supuesto oráculo en hexámetros dactílicos ${ }^{7}$, que Lisístrata lee a las mujeres que han ocupado la Acrópolis para darles confianza en el éxito final de su empresa. El oráculo aquí parodiado ofrece

${ }^{5}$ A saber, D. 5.343, 8.80, 13.126, 24.299, 27.333, 28.145, 30.295, 36.14, 47.294 у 48.802 .

${ }^{6}$ Los ejemplos (en cursiva los de final de verso) son: $1.128,289,3.533,7.143,9.484$, $10.353,11.294,12.377,396,13.420$ y 14.547.

${ }^{7}$ Las relaciones entre los oráculos y la épica han sido bien estudiadas desde el antiguo trabajo de Moore (1921). Véanse también Fernández Delgado 1986, 1991 y Nieto 1988; los libros de Willi 2003 y Platter 2007 incluyen sendos capítulos de interés sobre ese tema. 
algunos aspectos dignos de comentario. Por una parte, comparte casi literalmente la forma de expresar la inversión de situaciones con un verso de Teog-

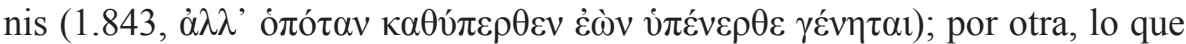
se refiere al uso de $\alpha \lambda \lambda$ ' ó ${ }^{\prime} \tau \alpha \nu$ como comienzo de un verso oracular, pues con en esa posición y con ese contenido aparece en treinta y dos ejemplos de los Oráculos sibilinos y también en el pasaje de Eq. 197, ya comentado y, como principio de verso pero sin formar parte de un oráculo, en $V .715$. En la épica antigua, ózó $\alpha \alpha$, cuyos miembros suelen editarse, además, por separado, aparece muy poco. En Homero, donde lo más frecuente es $\alpha \lambda \lambda$ ' ő $\tau \varepsilon$ $\delta \eta ́$ (ciento seis ejemplos, siempre a comienzo de verso), la encontramos en $\mathrm{Il}$. XVI 62, XX 316, XXI 340, Od. X 508, XI 17, en ninguno de los cuales es apreciable un contenido oracular ni es ó ó $\tau \alpha v$ comienzo de verso; los Himnos Homéricos ofrecen dos ejemplos, h.Ap. 71, h.Merc. 287 con características similares a los de Homero; solo en Hesíodo ( $O p$. 571) hallamos un ejemplo similar por posición y contexto al de esos comienzos oraculares parodiados por Aristófanes. En cuanto a la poesía de los siglos VIII-V, la presencia de ó ó́ $\alpha \alpha$ es relativamente amplia, pero el contexto métrico y de contenido es completamente distinto. Las peculiaridades de empleo señaladas permiten concluir que en su empleo de $\alpha \lambda \lambda$ ' ó ó$_{\tau} \alpha \nu$ Aristófanes parodia directamente a los oráculos.

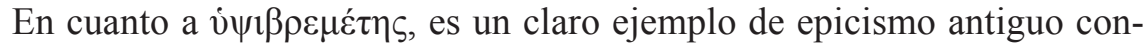
servado por Aristófanes. Repetidos exactamente, nombre y epíteto encabezan verso en seis ejemplos de Homero (Il. I 354, XII 68, XIV 54, XVI 121; Od. V 4 y XXIII 331), posición que se mantiene en los tres ejemplos de Hesíodo (Th. 568, en acusativo, 601 y $O p$. 8). Sorprendentemente, la épica tardía no ofrece más que un ejemplo, en las Argonáuticas Órficas (v. 1278), en igual caso y sede métrica que en el ejemplo de Aristófanes. El cómico es, además, el único testigo de un empleo épico antiguo, ya que el epíteto no es utilizado por ningún autor entre los siglos VIII y V a. C. ${ }^{8}$.

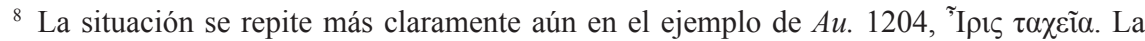
pareja constituida por la diosa y su epíteto no la utiliza ningún autor entre VIII y V a. C. ni tampoco aparece en la épica tardía, sino que solo se encuentra en cuatro ejemplos de la Ilíada: VIII 399, XI 186, XV 158 y XXIV 144, siempre en la expresión formular de principio de

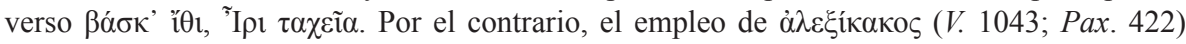
cuenta con precedentes en la épica antigua (Il X 20; Hes., Op. 123), clásica (Panyas. $12.13=$ 16.13) y, sobre todo, postclásica (36 ejemplos en Nonno). 


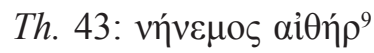

Son palabras que pronuncia el criado de Agatón cuando Eurípides y su pariente acuden a casa de aquel en busca de vestimenta femenina que permita que este último se pueda introducir sin que lo reconozcan como varón en la fiesta de Deméter y Perséfone, exclusiva de las mujeres. Aparte de los ejemplos del cómico, lo vemos en un verso de Homero (Il. VIII 556) y en otro de Quinto de Esmirna (14.91).

Resulta sorprendente que, a pesar de que la crítica a Eurípides sea tema muy principal en esta comedia, el epíteto no se encuentre en ninguna de sus tragedias, sino, como hemos dicho, en Homero y la épica. Tampoco lo documenta ningún otro autor del período que analizamos ${ }^{10}$, por lo que Aristófanes es el único en conservar un epicismo que tiene representación (por escasa que sea) en la épica de todas la épocas. Un ejemplo muy parecido es el del v. 108 de esta misma pieza ${ }^{11}$.

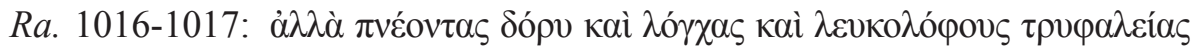

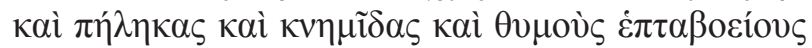

En su disputa con Eurípides, Esquilo se jacta de las cualidades que adornan a los hombres que han aprendido de sus tragedias. Emplea tetrámetros anapésticos catalécticos, lo que haría utilizable a cualquiera de sus términos, que además son claramente épicos, en versos dactílicos.

Este ejemplo es un buen exponente, a nuestro entender, de la utilización con fines cómicos de los términos de la épica antigua: seguramente, al oír cualquiera de esas palabras, el espíritu del público se trasladaba al ambiente y a las expresiones típicas de ese género, pero la comicidad consiste, en este

${ }^{9}$ Lo repite, en tono de burla, en el v. 51 el pariente de Eurípides, a quien los escolios identifican con su suegro, Mnesíloco; la expresión se encuentra también en $A u .778$.

${ }^{10}$ En su amplio comentario de la pieza, Prato 2001 explica que en estas palabras del criado de Agatón tenemos un ejemplo del tópico de la calma de la naturaleza, cuya primera expresión está en Alcmán ( $P M G$ 89).

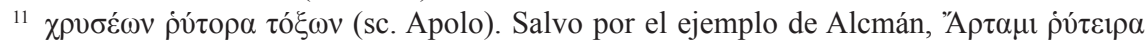

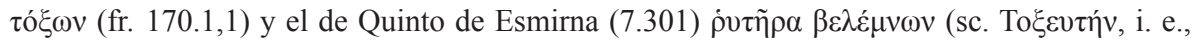
Apolo), Aristófanes es el único en conservar un epíteto que tiene presencia, aunque escasa,

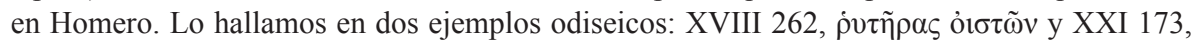

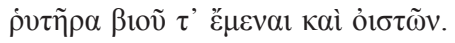


caso, en una asociación de epítetos y palabras que se aleja de la que se da en Homero y la épica en general.

Reduciendo el análisis a $\dot{\varepsilon} \tau \alpha \beta$ ßóíovs, encontramos que se trata de un epíteto épico con representación tanto en la épica antigua (Il. VII 220, 222, 245, 266, XI 545) como en la postclásica (Opp., C. 217; Nonn., D. 22.305, 28.62), pero en todos ellos (salvo en el ejemplo de Opiano Anazarbense) el

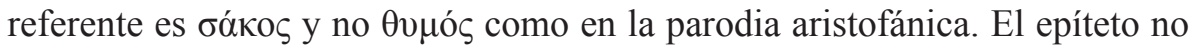
aparece en ninguno de los autores del período VIII-V a. C., lo que hace una vez más al cómico testigo único de un epicismo, aunque sea deformado para adaptarlo a sus intereses.

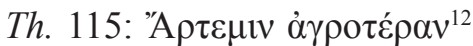

Se trata de un epíteto que por sí solo o acompañando al nombre sirve para referirse a Ártemis.

Tanto en la épica antigua como en la postclásica su representación se reduce a un ejemplo: el de Homero, en nominativo, está en Il. XXI 471; el tardío, totalmente similar al de Homero, es de Nonno (D. 48.349).

También hay ejemplos en la literatura de los siglos VIII-V. Uno lo hallamos en Baquílides (11.37, 'А

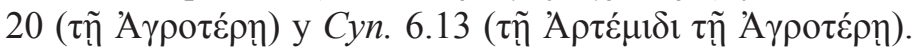

Se trata de un auténtico epíteto épico aunque con escasos ejemplos. Aristófanes es solo uno más de los que lo emplean.

\section{Epitetos épicos aristofánicos}

En este grupo analizaremos, sin dividirlo explícitamente en dos subgrupos aunque en cada ejemplo señalaremos su pertenencia a uno u otro de ellos, términos de dos clases. Unos son epítetos que recuerdan a la épica pero que no aparecen en Homero aunque sí en los épicos postclásicos; podríamos decir de ellos que son epicismos avant la lettre (que en alguna rara ocasión presentan ejemplos en los autores comprendidos entre los siglos VIII y V a. C.). Otros son epítetos que, a pesar de su apariencia épica y de sus posibilidades de

${ }^{12}$ El epíteto se encuentra también, en vocativo, como equivalente del nombre de la diosa, en la canción del enviado de Esparta tras la fiesta final de Lisístrata (v. 1262). 
adaptación al esquema métrico del hexámetro, no tienen representación sino en Aristófanes, que se convierte así en un verdadero creador de epicismos ${ }^{13}$.

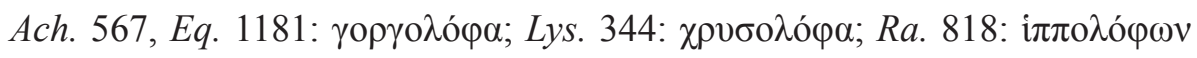

La estructura prosódica de los tres epítetos, un coriambo, permite en principio su integración en versos de ritmo dactílico ${ }^{14}$, pero el hecho es que el segundo de ellos carece de ejemplos en la épica, antigua o moderna, y entre los siglos VIII-V a. C. apenas lo encontramos en Anacreonte (fr. 1, 11+3+6.18) y Baquílides (fr. 2.13, como epíteto de Ares). En cuanto al primero ${ }^{15}$ y el tercero, se trata de verdaderos hápax ${ }^{16}$.

Esta situación reproduce casi exactamente la que hemos de reflejar en n. 21 acerca de los adjetivos compuestos sobre $\check{\varepsilon} \chi \omega$, pues la épica antigua carece por entero de epítetos formados mediante $-\lambda \circ \varphi \circ \varsigma$ (aunque $\lambda$ ópos es

${ }^{13}$ Los comentarios modernos de Aristófanes suelen sugerir algún epíteto de la épica anterior que haya podido servir de modelo al que crea aquel; pero ello refuerza, creemos, nuestra idea de la vigencia de la épica en el espíritu del público del cómico y las posibilidades que ello le da para hacer reír. El fenómeno se integra en el rasgo de comicidad basado en su modo peculiar de utilizar el lenguaje. Estos epítetos épicos aristofánicos son parecidos a

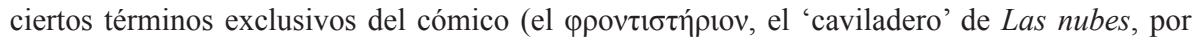
ejemplo), bien construidos pero sin carta de naturaleza en la lengua griega. Han sido objeto de numerosos estudios, desde el vetusto de Peppler 1902, pasando por las tesis doctorales de Sánchez Ruipérez 1948 y Rodríguez Monescillo 1972. Más recientemente se han ocupado del fenómeno la propia Rodríguez Monescillo 1985 y, con gran detalle y aparato bibliográfico, López Eire 1986, 1996 y Gil 1996, pp. 51-55. El posible carácter épico de alguno de esos términos es total o casi totalmente silenciado en todos ellos.

${ }^{14}$ Sin embargo, la inclusión de los nominativos o vocativos acabados en - $\lambda$ ó $\varphi \alpha$ sería problemática: en primer lugar, por su $\bar{\alpha}$ final, un dorismo que, reduciendo la argumentación a $\chi \rho v \sigma o \lambda \hat{o} \varphi \alpha$, ya resulta extraño en el conjunto del himno en que aparece, donde abundan las

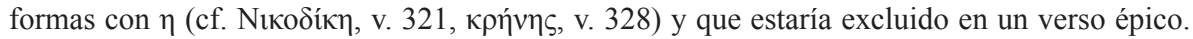
Por otra parte, entraría en cualquiera de los tres primeros pies de un hexámetro, coincidiendo su final con las cesuras trihemímeres, pentemímeres y heptemímeres, respectivamente, pero no al comienzo de los pies $4 .^{\circ}$, pues implicaría un verso con diéresis media, una pausa muy evitada en el hexámetro (cf. García Romero 1983), ni $5 .^{\circ}$, pues, salvo que fuera seguida por una enclítica, dejaría una pausa ante el anceps final del verso, algo rítmicamente inaceptable y de lo que, que sepamos, no existen ejemplos.

${ }^{15}$ Lo recoge el léxico de Hesiquio ( $\gamma$ 846), que lo explica haciendo referencia al verso de los Acarnienses arriba citado.

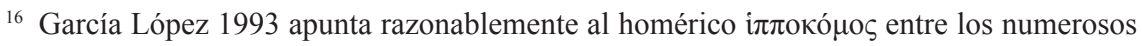
compuestos de ï $\pi$ o $\varsigma$ como origen del neologismo aristofánico. 
palabra muy común en ella), pero los encontramos, aunque escasamente, salvo en Nonno, en la épica tardía, en la que, sin embargo, no aparece jamás i $\pi \pi \circ \lambda$ ó $\varphi \circ /-\varphi \alpha^{17}$.

Como en otros ejemplos analizados en este grupo, Aristófanes se comporta prácticamente como un creador de epítetos épicos.

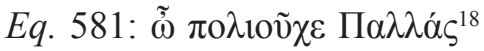

Es preciso señalar ante todo que la pareja constituida por el epíteto $\pi \circ \lambda$ เõ̃ $\chi \varsigma$ y la denominación П $\alpha \lambda \lambda \alpha$ ás para Atenea, que aparece en un himno dentro de esta comedia, no es integrable en el esquema métrico del hexámetro, por lo que no cabe encontrarla literalmente en el género épico; pero sí lo podría ser la unión del epíteto con el nombre propio de Atenea ${ }^{19}$.

La épica antigua no conoce ejemplos de ese adjetivo, por lo que, excluidas como se ha dicho las razones métricas, el hecho podría obedecer a que en la época que reflejan los poemas épicos antiguos no se conocen aún las ciudades-estado y sus divinidades políade ${ }^{20}$, emparejamiento que surgió tras las guerras Médicas, de cuyo resultado victorioso atribuyeron los griegos buena parte a los dioses y a los héroes y se sintieron impelidos a tributarles honras especiales, inmersos en un estado de exaltación religiosa que Nilsson llamó «religión patriótica nacional». La épica antigua ni siquiera ofrece adjetivos compuestos sobre $\pi$ ó $\lambda 1 \zeta$, aunque se cuentan por centenares los ejemplos de esa palabra.

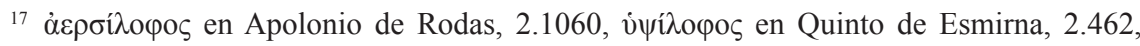

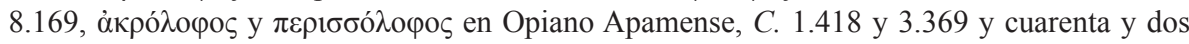

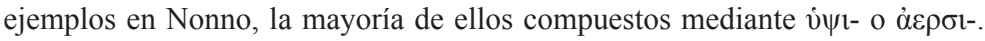

${ }^{18}$ Lo que decimos de este ejemplo es aplicable también a los otros dos casos ( $N u$. 602,

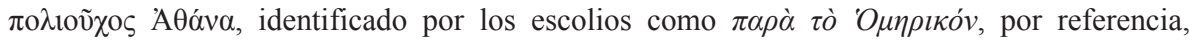

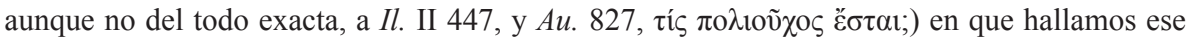
epíteto en Aristófanes.

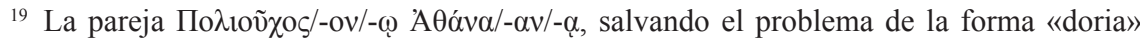
del nombre de la diosa, sería un perfecto final de hexámetro desde la cesura heptemímeres, con respeto del puente de Hermann. Por otra parte, si se cambiara el orden de palabras, $\tilde{\omega}$ $\Pi \alpha \lambda \lambda \dot{\alpha} \varsigma$ По $\lambda$ เoṽ $\chi \varepsilon$ podría iniciar un hexámetro hasta la cesura trocaica.

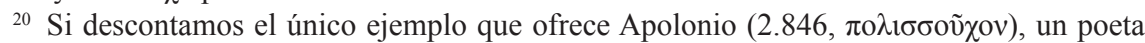
épico tardío por la época en que vivió, pero antiguo por su respeto al modelo homérico en tantos detalles. De una ausencia semejante, debida, probablemente, a las mismas razones, habremos de hacernos eco cuando analicemos el epíteto $\kappa \lambda \eta ฺ \delta o \tilde{\chi o s . ~}$ 
En la épica tardía sí los hay y, aunque no son muy numerosos, en todas las ocasiones se trata de $\pi \mathrm{o} \lambda \mathrm{\imath}(\sigma \sigma) \mathrm{o} \tilde{\chi} \chi \zeta$, precisamente la forma que hallamos en Aristófanes. Los ejemplos tardíos pertenecen a Opiano Apamense (C. 4.4,

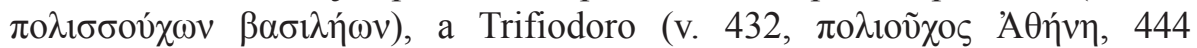

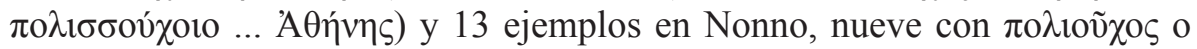

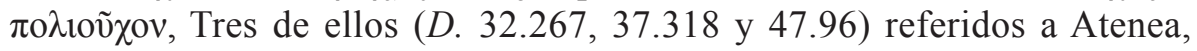
como el ejemplo de Aristófanes y cuatro con la forma $\pi 0 \lambda 1 \sigma \sigma o \tilde{\chi} \chi \circ$, , dos de ellos (3.262 y 44.42) igualmente referidos a Atenea, llamada $\theta \varepsilon \alpha i ́ v \eta \varsigma$,

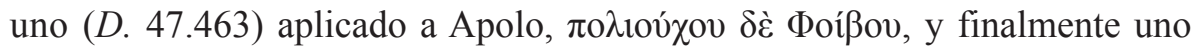
(D. 25.164) sin atribución a ningún $\operatorname{dios}^{21}$. Esta presencia en la épica tardía de un término aparentemente épico usado por Aristófanes sin presencia en la épica antigua es un buen ejemplo de la primera clase que incluimos en este grupo $^{22}$.

La búsqueda de $\pi 0 \lambda 1(\sigma \sigma)$ oṽ $\chi 0 \varsigma$ entre los siglos VIII-V proporciona datos interesantes. Esquilo, paradigmático ejemplo del sentimiento religioso recién descrito, ofrece ocho ejemplos en los que el adjetivo se les aplica a los dioses en general $^{23}$; pero fuera del trágico de Eleusis $-\mathrm{y}$ del ejemplo de Platón que citamos a continuación - la pareja del adjetivo es constantemente la diosa Atenea. A ella se refiere el único ejemplo de Heródoto (I 160.9, غ̇ $\xi$ ipoṽ [en

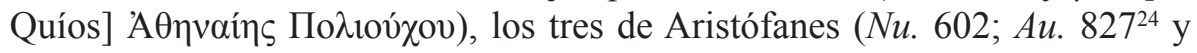

${ }^{21}$ Resulta también sorprendente, porque se aparta del normal proceder por parte de autores de diversas épocas y géneros, la escasísima representación en la épica de todos los tiempos de términos compuestos mediante el verbo है $\chi \omega$ como segundo formante. De hecho,

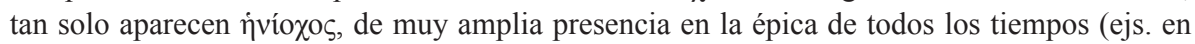

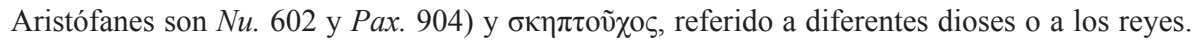
En la épica antigua no está, salvo en Homero (Il. I 279, II 86, XIV 93; Od. II 231, IV 64, VIII 41, VIII 47, con el adjetivo siempre referido a los reyes) y en h.Mart. 6; en la tardía lo encontramos, con más variedad de referentes, en Opiano Apamense (C. 2.41, 3.1, 5.675), Trifiodoro (267), Nonno (veintinueve ejemplos) y Quinto de Esmirna (3.518). En cambio, sin concretar autores, número de ejemplos ni localización de los mismos, mencionaremos, aparte

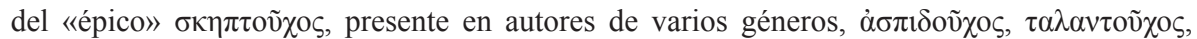

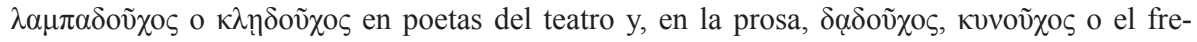

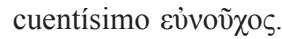

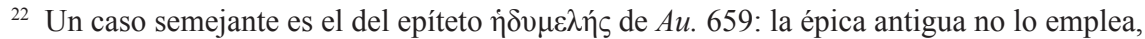
pero sí lo hace Nonno, en cuyas Dionysiaca aparece cinco veces (1.39, 466, 20.332, 24.217 y 29.287).

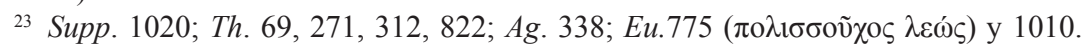

${ }^{24}$ Un buen ejemplo de la capacidad cómica de Aristófanes y del carácter eminentemente ateniense de sus comedias: ante la fundación de la nueva ciudad, Pistetero pregunta a qué 
Lys. $345^{25}$, dentro de un himno a cargo de las mujeres jóvenes de Atenas en el que se mencionan otros tres epítetos de la diosa, a saber, $\kappa \lambda \eta n \delta o \tilde{\chi} \chi \sigma$,

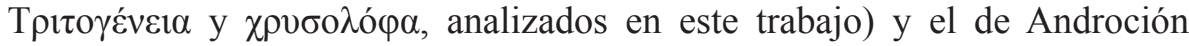

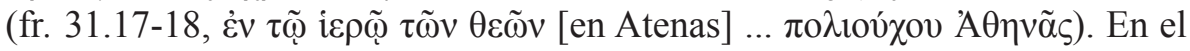
ejemplo de Platón $(L g .921$ c) el referente es Zeus.

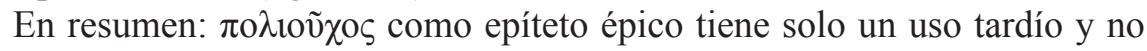
sabemos hasta qué punto pudieron influir en su extensión a la última épica Aristófanes y la poesía hímnica que encontramos en los ejemplos del drama ${ }^{26}$. Los ejemplos señalados en último lugar, con su mayoritaria referencia a Palas Atenea, lo que puede ser otra razón para explicar su ausencia de la épica homérica ${ }^{27}$, apuntan al empleo por Aristófanes de un epíteto ateniense posteriormente acogido por la épica tardía.

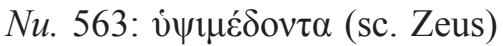

Forma parte de un himno clético dentro de la parábasis de esta pieza ${ }^{28}$. Pese a que su estructura prosódica permitiría su sencilla integración en un verso dactílico, el hecho es que la épica antigua apenas ofrece dos ejemplos en

divinidad van a tener por políade, y cuando Evélpides contesta que a qué otra sino a Atenea, aquel le responde que no pueden hacer patrona de su ciudad, un oasis de paz, a una diosa que se representa revestida de panoplia completa.

${ }^{25}$ En realidad, $\pi$ o $\lambda$ 1oṽ $\chi \varepsilon$ funciona en este contexto como sustituto del nombre de la diosa, cuyo epíteto es $\chi \rho v \sigma o \lambda o ́ \varphi \alpha$, que analizamos en otro lugar, colocado en el verso anterior.

${ }^{26}$ Cabe simplemente pensar que, fuera cual fuera la autenticidad de sus propios sentimientos religiosos, el hecho es que nuestro poeta escribe para la ciudad de Atenas y en un momento en que la profunda religiosidad que se manifestó en tiempos de Esquilo empezaba a decaer, pero todavía mantenía buena parte de su vigor: no hay que olvidar, por otra parte, que por convicción o por convención, Aristófanes se nos presenta como un conservador. Amplia discusión sobre las ideas políticas y religiosas del cómico puede encontrarse en Corsini 1986 y Rodríguez Monescillo 1985, respectivamente.

${ }^{27}$ Hasta cierto punto, estos versos de Aristófanes, una plegaria a la diosa protectora de su ciudad, ofrecen semejanzas con un discutido pasaje de la Ilíada (VI 86-88, repetido con leves variaciones en 269-278) en el que las referencias a Atenea han inducido a muchos críticos a considerarlo una interpolación ateniense, interpretación que, con reservas, aceptan García Blanco y Macía 1998, ad VI 88 ss., y rechaza Kirk 1990, ad VI 87-94.

${ }^{28} \mathrm{La}$ inserción de himnos a los dioses es un hecho bastante común en las partes de la parábasis llamadas «oda» y «antoda», como señala Guidorizzi 1996, ad loc., quien, sin embargo, no menciona el posible epicismo de este epíteto. 
Hesíodo $^{29}$ y que entre VIII y V a. C. lo encontramos en un ejemplo de Píndaro (N. 2.19) y en dos de Baquílides (Ep. 1.1; Dyth. 1.51).

En la épica tardía - exclusivamente en Nonno ${ }^{30}$ — volvemos a encontrarnos con ese epíteto, por lo que puede que estemos ante un caso de empleo por Aristófanes de un epicismo nuevo que tendría éxito posterior, aunque también podría pensarse que Píndaro y Baquílides son el modelo del uso épico postclásico.

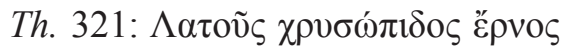

Solamente el primer verso de la Titanomaquia, un poema épico arcaico anónimo, ofrece un ejemplo de ese epíteto ${ }^{31}$, referido allí a los peces, por lo que parece que estamos ante un epicismo aristofánico; pero si documenta un epicismo anterior, lo ha hecho adaptándolo a sus necesidades, cambiando el referente, por lo que entendemos que se trata de un epicismo propio, no de una imitación.

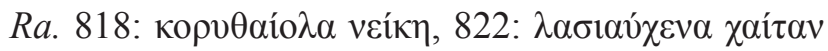

Palabras del coro, alusivas al lenguaje de Esquilo, antes de que él y Eurípides compitan por el trono de la tragedia en el Hades ${ }^{32}$.

Excepto por el dorismo $\chi \alpha i \tau \alpha v$, ambas expresiones son perfectamente utilizables en un hexámetro épico; sin embargo nos encontramos con una

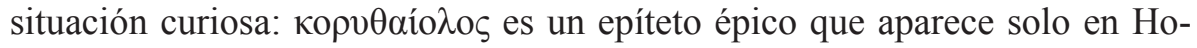
mero y en Nonno; en el primero es epíteto exclusivo de la Ilíada y de Héctor, seguido de cuyo nombre en nominativo se da en treinta y seis de un total de

29 Th. 259, fr. 156.1. En el $T L G$ la palabra se divide, pero otras ediciones reúnen sus dos componentes.

${ }^{30}$ Treinta y tres ejemplos, referidos mayoritariamente a Zeus y ubicados casi todos en final de verso.

31 Muy al contrario de lo que sucede con otros epítetos construidos sobre ö $\psi$, como

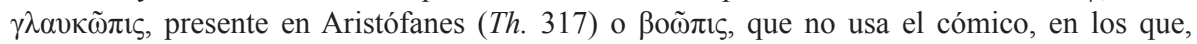
según Prato 2001, se inspira.

32 Los epítetos no pretenden reproducir términos que use Esquilo, quien, efectivamente, no los utiliza, sino caracterizar la solemnidad y ampulosidad de su lenguaje. En los autores de los siglos VIII-V a. C. no hay más ejemplo que el del v. 350 de Antígona, aplicado a ï $\pi \pi$ os. Del aire homérico de esas expresiones se hace eco Del Corno 1984. 
treinta y ocho ejemplos ${ }^{33}$, en tanto que en los dieciocho ejemplos que ofrece el de Panópolis no hay ninguna regularidad semejante, aunque jamás, como sucede en el ejemplo aristofánico, se atribuye a una entidad abstracta.

Aparentemente, Aristófanes ha creado un epicismo mediante el empareja-

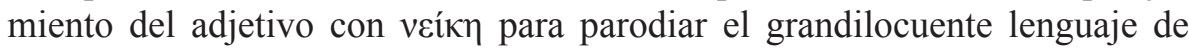
Esquilo.

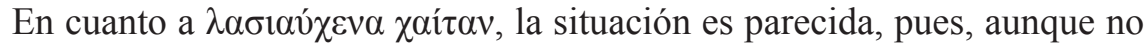
se da en Homero, lo encontramos en los Himnos Homéricos (h.Merc. 224; h.Bacch. 46) y hay un ejemplo en Opiano Apamense (C. 1.183), pero lo propio de Aristófanes es su emparejamiento con $\chi \alpha i \tau \alpha v^{34}$.

\section{Epicismos aparentes pero no confirmados}

Pese a su apariencia y sus posibilidades prosódicas, hay que pensar que los epítetos de este grupo aluden al ambiente de la lírica o al de la tragedia y que son esos géneros los que el poeta trata de sugerir a su público y con los que probablemente intenta provocar su risa.

Como veremos, en este grupo hay ejemplos susceptibles de ser analizados también en otros, particularmente en el de los epítetos épicos aristofánicos.

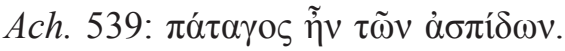

Aunque por su contenido la expresión podría entrar en el contexto bélico de la Ilíada, la estructura prosódica no se ajusta al hexámetro, de modo que no encontramos en Homero ningún ejemplo semejante ${ }^{35}$; en cambio, hallamos

${ }^{33}$ Excepciones son XX 38, en interior de verso como epíteto de Ares, y XXII 471, sepa-

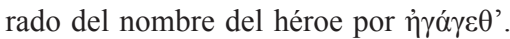

${ }^{34}$ Las circunstancias de uso de los dos términos de ese epíteto son notables: en la épica antigua hay un empleo abundante del adjetivo $\lambda \alpha ́ \sigma t o \varsigma$, pero no se usa en composición, cosa

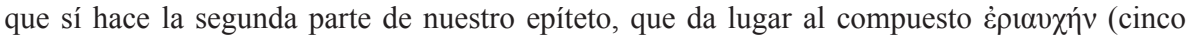
ejemplos en Homero, con ï $\pi \pi \mathrm{ol} /$-ov y un ejemplo en el h.Hom. 32.9, con $\pi \dot{\omega} \lambda \mathrm{ov}$, igual que sucede en el muy tardío Juan de Gaza). La épica postclásica, como acabamos de señalar, apenas conoce ejemplos de composición de epítetos con $\alpha \hat{\chi} \chi \eta ́ v$, pero ofrece algunos con $\theta \rho i ́ \xi$ como segundo formante precedido de $\lambda \alpha ́ \sigma 10 \varsigma$ en cinco casos (Opp., H. 4.369; Opp., C. 1.474, 3.327; Nonn., D. 6.185, 7.275).

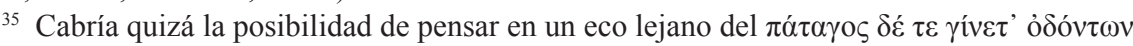
de $I l$. XIII 283. En cuanto a à $\sigma \pi i ́ \delta \omega v$, crético inevitable, no entra en ninguna posición del ver- 


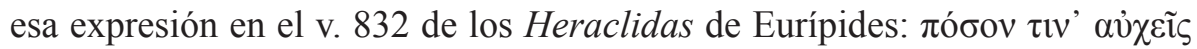
$\pi \alpha ́ \tau \alpha \gamma \circ \varsigma \alpha \dot{\alpha} \sigma \pi i \delta \omega v \beta \rho \varepsilon ́ \mu \varepsilon \imath v$, dentro de un pasaje en trímetros yámbicos, como el ejemplo de Aristófanes ${ }^{36}$.

En Homero, pues, la presencia del conjunto y de $\alpha \sigma \pi i ́ \delta \omega v$ es nula, y lo mismo vale para el género épico ${ }^{37}$.

La situación no es mucho mejor en Homero respecto a $\pi \alpha ́ \tau \alpha \gamma o \zeta$, cuya estructura prosódica (tríbraco) admite la conversión en anapesto mediante el alargamiento por posición y, en consecuencia, su presencia en distintos segmentos del hexámetro. Se encuentra tan solo en cuatro versos de la Ilíada (XIII 283, XVI 769, XXI 9 387), siempre inmediatamente detrás de la cesura pentemímeres y acompañado de diversos genitivos subjetivos. Tampoco en la épica encontramos apenas nada semejante al uso aristofánico, si exceptua-

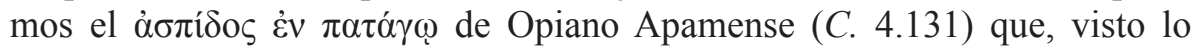
visto, supone una auténtica novedad en el género. Los ejemplos de Nonno, que emplea el sustantivo veintitrés veces, frecuentemente asociado al adjetivo $\beta \rho 0 v \tau \alpha i ̃ o s$, no son comparables al aparente homerismo (o epicismo) del ejemplo de Aristófanes.

Por último, la búsqueda de $\pi \alpha ́ \tau \alpha \gamma o \varsigma$ entre los siglos VIII-V a. C. nos proporciona unos resultados semejantes, con escaso empleo del término: ejemplos sin relación con el nuestro (Pi., P. 1.24; A., Th. 239; Anacr., PMG 11b.2) y ejemplos relativamente similares en tragedia, uno en Esquilo (Th. 103) y dos en Sófocles (Tr. 517; Ant. 125). Este detalle nos induce a pensar en que la imitación —o el uso común e independiente de una expresión determinada - de estas palabras por Aristófanes tiene como referente a la tragedia

so. La palabra ỏotíç aparece noventa y una veces en Homero (dos en la Odisea) en diferentes casos que proporcionan siempre un dáctilo; aparece también dos veces (Il. II 554, XVI 167, ambas en final de verso) el compuesto $\alpha \sigma \pi \imath \delta 1 \omega ́ \tau \alpha \varsigma$ y $\dot{\pi} \alpha \sigma \pi i \delta 1 \alpha$, con - $\alpha$ alargada ante $\pi \rho-$, en tres ocasiones, Il. XIII 158, 807, XVI 609.

${ }^{36} \mathrm{La}$ fecha más probable para la representación de esa tragedia es entre 430 y 427 a. C. Ya que el 425 es la de Acarnienses, es posible, dada la comunidad de sentimientos antiespartanos que se perciben en ambas obras, que este verso de Aristófanes contenga una parodia de Eurípides, aunque el hecho no se señala ni en comentarios de Eurípides (véase, por ejemplo, Calderón 2007) ni de Aristófanes (véase Rodríguez Monescillo 1985; Gil 1995). La posibilidad de una imitación voluntaria por parte del cómico quizá se vea reforzada por el hecho de que $\pi \alpha ́ \tau \alpha \gamma o \varsigma$ ocupa la misma sede métrica, entre la pentemímeres y la heptemímeres, en este verso y en su posible modelo.

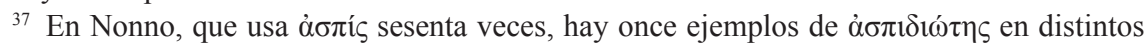
casos, siempre, como en Homero, en final absoluto de verso. 
(todas las recién mencionadas son de fecha más antigua que Acarnienses) más que a Homero y la épica.

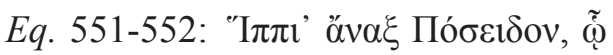

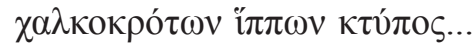

En los Caballeros y en Lisistrata hay algunos himnos a Posidón y Atenea, dioses estrechamente relacionados con la ciudad de Atenas, lo que justifica que se les eleven himnos en las comedias de Aristófanes, unas piezas de fuerte carácter local ateniense. En el caso de los Caballeros, además, se les invoca porque su protección resulta necesaria, pues tanto la acción dramática como su trasunto, la situación de la ciudad, pasan por un momento delicado en el que se decide su futuro.

En este ejemplo la épica se nos sugiere en la apelación ï $\pi \pi \imath^{\prime}$ ớ $v \alpha \xi$, cuya estructura prosódica, además, se ajusta al ritmo dactílico ${ }^{38}$ y en el adjetivo

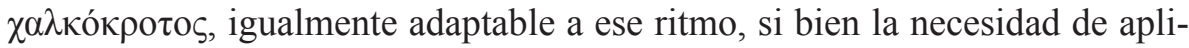

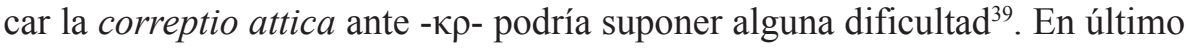
término, incluso la mención misma del dios podría entrar en consideración, pero no lo creemos oportuno, ya que la presencia de semejantes entidades es posible en cualquier contexto, no solo en la épica.

La épica antigua no conoce el adjetivo i $\pi \pi 10 \varsigma$, sino en sus compuestos

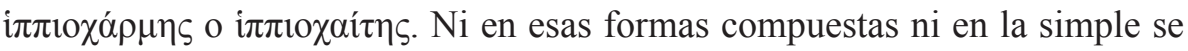
aplica a Posidón, si bien Nonno (D. 37.393) se acerca con su i $\pi \pi 10 \varsigma$ 'Evvođíyoısos. Solamente los épicos tardíos, que no usan las formas compuestas, emplean el adjetivo, pero lo refieren a Ares (Trifiodoro, v. 1) o a Argos (Nonn., D. 47.517, 713), siempre en posición final de verso.

La situación cambia en los ejemplos datables entre VIII y V a. C. En todos ellos el adjetivo se muestra en su forma simple y, además, su relación con Posidón es constante. Considerando que la mitad de esos ejemplos se encuentran en la tragedia, entendemos que el posible eco aristofánico lo es de ese

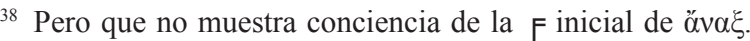

${ }^{39}$ La correptio attica es un fenómeno que apenas tiene representación en los yambógrafos jonios y que en Homero es también poco frecuente. En la mayoría de los pocos ejemplos en que se produce las dos consonantes implicadas pertenecen al mismo morfema o semantema, por lo que es más rara en palabras como la aquí implicada, donde el grupo $-\kappa \rho$ - pertenece a la segunda parte del compuesto (cf. Korzeniewski 1968, p. 21). 
género literario y no de la épica, donde, como hemos visto, no se pueden hallar paralelos ${ }^{40}$.

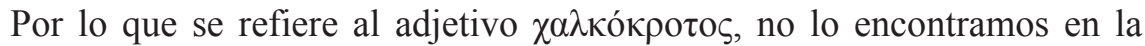

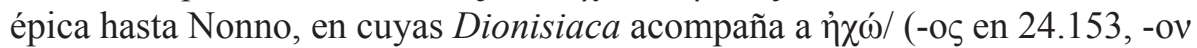
en 15.55 y 39.127 ) en tres ocasiones. Entre los siglos VIII y V no hay ejem-

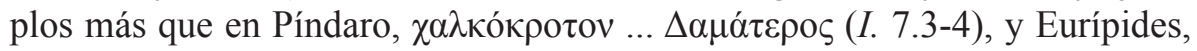

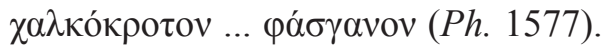

En las apariciones del nombre de Posidón no nos detendremos por las razones apuntadas más arriba, que se ven confirmadas por el rastreo mediante el $T L G^{41}$.

En resumen, podemos decir que el conjunto no apunta directamente a imitación épica y que, entre sus integrantes, dejando aparte la mención de Posidón, el empleo del adjetivo simple, ï $\pi$ tos, apunta más a la lírica y al

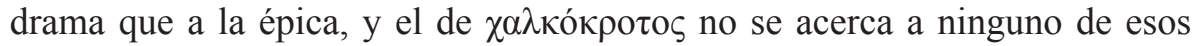
géneros especialmente, sino que parece una palabra plenamente independiente en el cómico. Podría entenderse como uno de los casos a los que aludíamos en la presentación de este epígrafe de «epicismo aristofánico» dentro de un conjunto mayor y no aislado en el comentario.

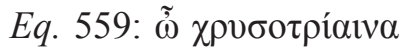

Como ï $\pi \pi$ เ del ejemplo anterior, es un epíteto dedicado a Posidón. Solo en este verso utiliza Aristófanes un compuesto para mencionar el tridente, que

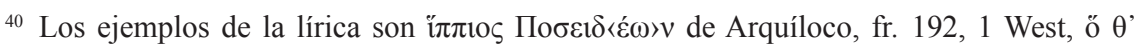

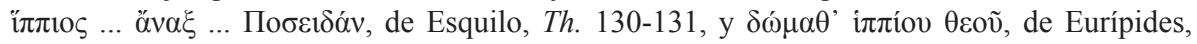

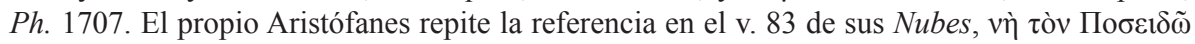

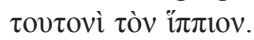

${ }^{41}$ El detalle es complicado. Como hecho curioso indicaré, no obstante, que hay ciento noventa y un ejemplos en la épica, de los que ciento uno están en la épica temprana, con Homero (ochenta y cinco) a la cabeza, muy lejos de los dieciséis de Hesíodo o Apolonio y de los treinta de Nonno. Igualmente curiosa es la presencia o ausencia de epítetos de acompañamiento para el nombre del dios, diferente en la épica antigua y en la tardía. En los treinta ejemplos de Nonno ni una sola vez

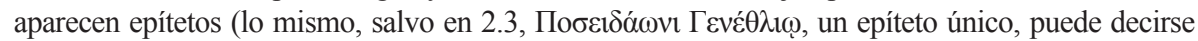
para Apolonio de Rodas), en tanto que en los ejemplos de la épica antigua la presencia de un epí-

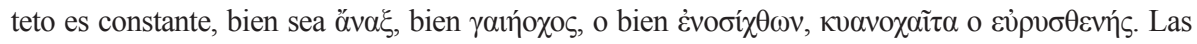
mismas diferencias de empleo o carencia de epíteto se aprecian en Píndaro, con solo dos epítetos (O. 6.58 y P. 4.45) en veintitrés empleos del nombre, o en Eurípides, con otros tres (Hipp. 45; Hel. 1585 e IT 1415) entre quince, frente a Sófocles, con cuatro epítetos en cinco empleos. 
simboliza al dios marino y con el que, por otra parte, lo identifica constantemente. En los otros dos ejemplos en que se menciona ese atributo, el v. 839 de esta comedia, donde el corifeo le dice al Morcillero que है $\chi \omega v ~ \tau \rho i ́ \alpha v \alpha v$

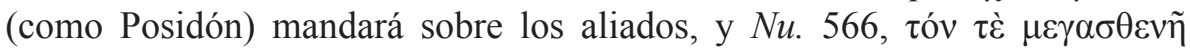

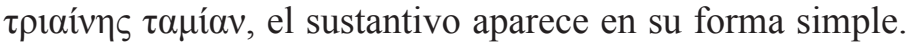

Dentro de la épica encontramos tres menciones del tridente en Homero (Il. XII 77; Od. IV 506, V 592). En ese género la palabra se presenta siempre en su forma simple y alude a Posidón. Asimismo en la épica tardía $\tau$ píaıva aparece exclusivamente en forma simple y siempre con el mismo referente ${ }^{42}$ y otro tanto sucede en la tragedia, donde los tres ejemplos de Esquilo (Supp. 218, 755; Pr. 925) y el único de Eurípides (Io. 282) se ajustan a ese mismo patrón.

La situación cambia radicalmente si observamos los ejemplos de la lírica de los siglos VII-V. En todos los casos, el tridente se presenta no solo referido a Posidón, sino en forma compuesta como equivalente al nombre mismo del dios. Lo vemos así en los seis ejemplos de Píndaro (cuatro veces

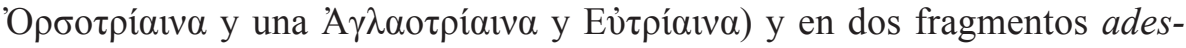
pota $^{43}$.

A la luz de lo dicho, parece evidente que la coincidencia en el empleo de este epíteto (o, simplemente, en el empleo de un epíteto compuesto que incluya la palabra tridente como referencia a Posidón) por parte de Aristófanes hay que buscarla en el terreno de la poesía lírica, con exclusión total de la épica (y de la tragedia), sin apelar a las no decisivas dificultades prosódicas -la aplicación de la correptio a la que hemos hecho ya referencia en un

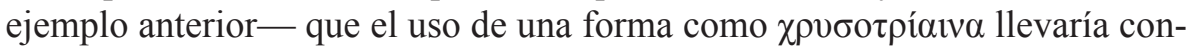
sigo en ese género. tiséis.

42 Véase Opiano Anazarbense, cinco ejemplos; Quinto de Esmirna, tres o Nonno, vein-

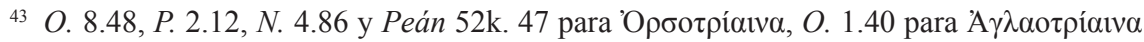

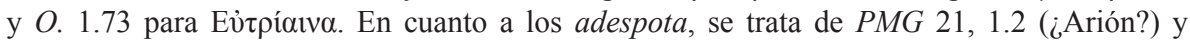

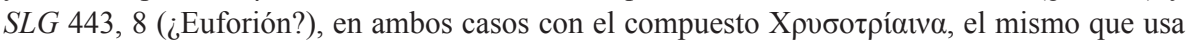
Aristófanes en el ejemplo que estamos comentando. 


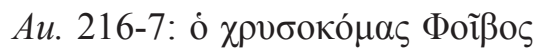

Se trata de un epíteto bien representado en la poesía griega, aunque con pocos ejemplos, en general, en los autores que lo documentan ${ }^{44}$. La épica reduce sus ejemplos, en su forma jonia desde luego ${ }^{45}$, al v. 947 de la Teogonía (aplicado a Dioniso) y a un par de ejemplos de Pablo Silenciario (VI d. C.) no referidos a dioses.

Varios autores entre VIII y V a. C. lo emplean, si bien, salvo en Píndaro, su presencia se reduce a un ejemplo; entre los trágicos, Eurípides es el único que lo documenta ${ }^{46}$. Semejante distribución nos mueve a pensar que el ámbito que se sugiere en esta ocasión con ese epíteto no es el de la épica, sino el de la lírica.

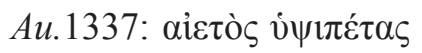

El parricida que, entre otros impostores, pretende aprovecharse del éxito de la empresa de Pistetero y Evélpides, recita unos versos que ya en los escolios se identifican como de Sófocles $^{47}$, por lo que es preciso asumir que es al trágico a quien se parodia. No obstante, el epíteto que analizamos ahora,

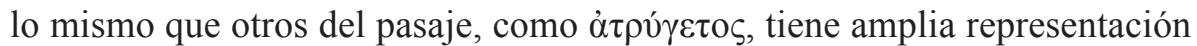
en la épica. En Homero lo encontramos, siempre referido al águila, en seis versos (Il. XII 201, 219, XIII 822, XXII 308; Od. XX 243, XXIV 538), varios de ellos completamente idénticos — salvo en la forma jónica para el epíteto-

${ }^{44}$ Zanetto $2000^{5}$ comenta ampliamente el ejemplo, pero no apunta ni en él ni en los demás pasajes de esa comedia analizados en este trabajo la posibilidad de que los epítetos aristofánicos sean un epicismo.

${ }^{45} \mathrm{La}$ forma dialectal «doria» de un epíteto podría excluir en principio su adscripción a la épica; pero la situación cambia si el epíteto aparece también en la épica en su forma «jonia», pues la dependencia de la lírica respecto a la épica en ese terreno es un hecho reconocido y bien conocido.

${ }^{46}$ Hay un ejemplo en una respuesta de la Pitia a Licurgo (Tyrt. 3b 4), otro en Alcmán $(S 1.1)$, otro en Alceo (fr. 327.3), otro en Anacreonte (13.2), tres en Píndaro (O. 6.41, 7.32; Peán 52e.41) y uno en Baquílides (Ep. 4.2); los cuatro de Eurípides son Supp. 975, Tro. 254, IA 548 e IT 1236. En cuanto al referente del epíteto, lo es Apolo casi siempre, en competencia con Eros.

${ }^{47}$ Perteneciente a su Enomao, es el fragmento 476 Radt. Naturalmente, ello no excluye que la presencia de ese (y de los otros epítetos del pasaje, por ejemplo à 1998, pp. 202-203) en Sófocles sea un epicismo; pero respetando nuestro método de análisis es a Sófocles y no a Homero a quien creemos que debemos ver en esos versos. 
con el empleo aristofánico, y también la épica tardía ofrece ejemplos, que encontramos en Opiano Anazarbense ( $H .1 .621)$, Pamprepio (3.183) y, sobre todo, Nonno (D. 11.295, 13.203, 15.282, 24.78 y 40.494), quien, salvo en 40.494, referido al águila, aplica el epíteto siempre a Zeus. Por el contrario, los poetas de los siglos VIII-V apenas lo documentan, salvo un ejemplo de Píndaro (P. 3.105) y otro de Eurípides (Hec. 1100).

Th. 315: Zعṽ $\mu \varepsilon \gamma \alpha \lambda \omega ́ v v \mu \varepsilon ~ \chi \rho v \sigma o \lambda v ́ \rho \alpha \tau \varepsilon$ (sc. Apolo)

El epíteto de Zeus carece de representación en la épica, sin que dicha ausencia pueda achacarse a imposibilidad métrica. Su presencia en la literatura de los siglos VIII-V es muy escasa. Se reduce a Alceo (fr. 34

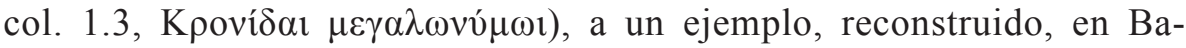

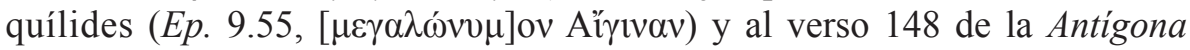

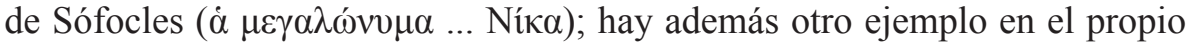
Aristófanes, $V$. 1518, donde se aplica el epíteto, con fines claramente cómicos, a los hijos de Carcino, un poetastro, a juicio de Aristófanes.

Sea porque lo toma de la lírica, o sea porque lo comparte con ella, el empleo paródico recién señalado del epíteto en las Avispas es coherente con el uso aristofánico de palabras y expresiones que sugieren otro tipo de obras: es receptor y transmisor de términos de otros géneros literarios y ocasionalmente los emplea para situar a su auditorio en esos géneros y para provocar la risa a su costa.

En cuanto a $\chi \rho v \sigma o \lambda u ́ \rho \alpha$, se trata de un completo hápax, tanto en Aristófanes como en el género literario y período temporal que analizamos, por lo que sería susceptible de incluirse entre los epicismos aristofánicos, analizados en el grupo anterior. Lo mismo sucede con $\dot{\alpha} \pi \varepsilon i \rho o \lambda \varepsilon \chi \tilde{\eta}$, otro epíteto referido a la misma diosa, que encontramos en el v. 119 de esta misma pieza y

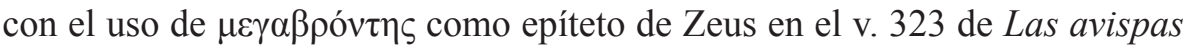

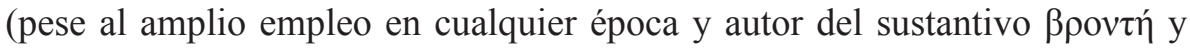
del verbo $\beta \rho o v \tau \alpha ́ \alpha \omega)$.

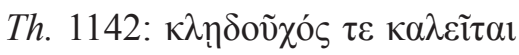

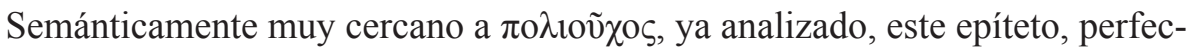
tamente aplicable a una divinidad políade, podría constituir unido al nombre de Atenea en diversos casos un final de hexámetro desde la heptemímeres, 
con espondeo en 4 . $^{\circ}$ pie y respeto del puente bucólico, un final alternativo

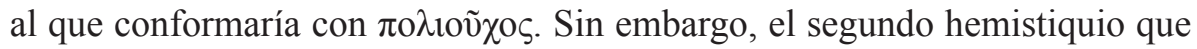
proporcionaría el ejemplo que comentamos iría precedido de la evitadísima diéresis media ${ }^{48}$, lo cual, en principio, le hace poco apto para usarse en poesía

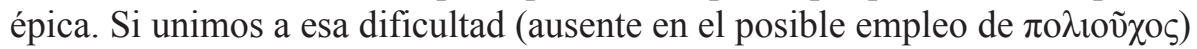
la de tipo histórico-cultural apuntada en ese otro epíteto, menor en este caso, porque, como veremos, no es Atenea la destinataria habitual del mismo, no nos sorprenderá que las condiciones de uso se parezcan en ambos adjetivos.

La épica antigua, y en este caso también la tardía, no usa nunca el epíteto $\kappa \lambda \eta ฺ \delta o \tilde{\chi} \propto \varsigma$, y en el período que media entre los siglos VIII-V su empleo es muy escaso y solo en el ejemplo de Aristófanes se aplica a Atenea, en tanto que los otros, todos en los poetas trágicos, lo refieren a distintos personajes: a Ío, Esquilo (Supp. 291); a Licurgo, a Eros y a la guardiana de las llaves del templo (de Dictina, es decir, de Ártemis), Eurípides (Hypsip. fr. I iv 18; Hipp. 540-541 e IT 131, respectivamente). Todas esas razones nos inducen a incluir este ejemplo en este grupo de falsos epicismos.

\section{Conclusiones}

A lo largo de este trabajo hemos descrito un modo constante de proceder por parte de Aristófanes en su utilización de adjetivos que por su forma y su significación hacen pensar en los de la épica a cualquiera que esté familiarizado con ese género.

Al igual que en el empleo de citas literales y versos o hemistiquios homéricos, que hemos analizado en trabajos anteriores, el poeta sabe que su público es capaz de captar la referencia. Fuera de su contexto natural, esas palabras pueden resultar ridículas y con ello el poeta consigue el efecto cómico que persigue.

Algunos epítetos se presentan en forma «doria», lo que en principio podría hacer suponer que la lírica (sobre todo la hímnica) y no la épica es el referente al que apuntan. Así sucede, en efecto, en unos pocos casos, que hemos agrupado en el apartado correspondiente, si bien es preciso señalar que algunos de esos epítetos líricos formaban parte de contextos más amplios donde otros podían ser catalogados como épicos.

48 Esas palabras podrían formar también el comienzo de un hexámetro, pero sería necesaria la abreviación en hiato de $\kappa \alpha \lambda \varepsilon i ̃ \tau \alpha$ para que no produjeran una tripodia dactílica y por ende un verso marcado por la muy evitada diéresis media (v. n. 14). 
La mayoría de los epítetos que parecen épicos pueden reunirse en dos grupos, que podrían ampliarse a tres. En el primero Aristófanes emplea epítetos que están en Homero. Frecuentemente en esos casos él es el único autor entre los siglos VIII-V a. C. que documenta el empleo del término, una característica que ya hemos señalado en el empleo de los otros tipos de homerismo ya analizados; pero hay también casos en que otros poetas, líricos o trágicos, lo hacen. En el segundo hemos podido ver a un Aristófanes creador de epicismos, a veces, ofreciendo términos que serán recogidos por la épica tardía, y a veces empleando verdaderos hápax, palabras que carecen de ejemplos en toda la literatura griega fuera de los que él documenta.

En cuanto a los aparentes epicismos, analizados en último lugar, los datos apuntan claramente a la lírica y al teatro más que a la épica como referentes de la parodia aristofánica.

\section{BiBLIOGRAFÍA}

Calderón, E. 2007: Eurípides V. Los heraclidas. Hécuba, Madrid, CSIC.

Corno, D. del 1984: Aristofane. Le rane, Milán, Fondazione Lorenzo Valla, Mondadori.

Corsini, E. 1986: «La polemica contro la religione di stato in Aristofane», en $L a$ polis e il suo teatro, Padua, pp. 149-183.

Fernández Delgado, J. A. 1986: Los oráculos y Hesíodo. Poesía oral mántica y gnómica griega, Cáceres, Universidad de Extremadura.

Fernández Delgado, J. A. 1991: «Die Orakel in der frühgriechischen Poesie», WJA 17, pp. 17-39.

García Blanco, J. y Macía, L. M. 1998: Homero. Ilíada II (cantos IV-IX), Madrid, CSIC.

García López, J. 1993: Aristófanes. Las ranas, Murcia, Servicio de Publicaciones de la Universidad de Murcia.

García Romero, F. 1983: «La cesura media en el hexámetro homérico», CFC (Gr.) 18, pp. 361-381.

Gil, L. 1995: Aristófanes. Comedias I. Los acarnienses. Los caballeros, Madrid, Gredos.

Gil, L. 1996: Aristófanes, Madrid, Gredos.

Guidorizzi, G. 1996: Aristofane. Le nuvole, Milán, Fondazione Lorenzo VallaMondadori.

Kirk, G. S. 1990: The Iliad: A Commentary. Vol. III: Books 5-8, Cambridge, CUP. Korzeniewski, D. 1968: Griechische Metrik, Darmstadt, WBG. 
Kugelmeier, Ch. 1996: Reflexe früher und zeitgenössicher Lyrik in der alten attischen Komödie, Stuttgart-Leipzig, Teubner.

López Eire, A. 1986: «La lengua de la comedia», Emerita 54, pp. 237-274.

López Eire, A. 1994: Aristófanes. Lisístrata. Salamanca, Hespérides.

López Eire, A. 1996: La lengua coloquial de la comedia aristofánica, Murcia, Ediciones de la Universidad de Murcia.

Macía, L. M. 1998: «Homero y Aristófanes», en Gil, L. (ed.), Corolla Complutensis, Madrid, UCM, pp. 199-209.

Macía, L. M. 2000: «Parodias de situaciones y versos homéricos en Aristófanes», Emerita 68, pp. 211-241.

Moore, C. H. 1921: «Prophecy in the Ancient Epic», HSCP 32, pp. 99-175.

Nieto, J. M. 1988: «Fórmulas homéricas y lenguaje oracular», Minerva 2, pp. 33-46.

Peppler, C. W. 1902: Comic terminations in Aristophanes and the Comics Fragments, Baltimore.

Platter, Ch. 2007: Aristophanes and the Carnival of Genres, Baltimore, John Murphy.

Prato, C. 2001: Le donne alle tesmoforie, Milán, Fondazione Lorenzo Valla-Mondadori.

Rodríguez Monescillo, E. 1972: Estudios sobre la lengua de Aristófanes (tesis doctoral), Madrid, UCM.

Rodríguez Monescillo, E. 1985: Aristófanes. Comedias I. Los acarnienses, Madrid, CSIC.

Sánchez Ruipérez, M. 1948: Los compuestos poéticos y paródicos en el estilo de Aristófanes (tesis doctoral), Madrid, UCM.

Schrader, C. 1985 (ed. y trad.): Herodoto, Historia. Libro VII, Madrid, Gredos.

Valk, M. van der 1964: Researches on the Text and Scholia of the Ilias, Leiden, E. J. Brill.

Willi, A. 2003: The Languages of Aristophanes, Oxford-Nueva York, OUP.

Zanetto, G. 20005: Aristofane. Gli uccelli, Milán, Fondazione Lorenzo Valla, Mondadori. 